University of Nebraska - Lincoln

DigitalCommons@University of Nebraska - Lincoln

2002

\title{
IMPACT OF TRANSFORMATIONAL LEADERSHIP ON FOLLOWER DEVELOPMENT AND PERFORMANCE: A FIELD EXPERIMENT
}

Taly Dvir

Dov Eden

Bruce Avolio

Boas Shamir

Follow this and additional works at: https://digitalcommons.unl.edu/managementfacpub

Part of the Business Administration, Management, and Operations Commons, Management Sciences and Quantitative Methods Commons, and the Strategic Management Policy Commons

This Article is brought to you for free and open access by the Management Department at DigitalCommons@University of Nebraska - Lincoln. It has been accepted for inclusion in Management Department Faculty Publications by an authorized administrator of DigitalCommons@University of Nebraska - Lincoln. 


\title{
IMPACT OF TRANSFORMATIONAL LEADERSHIP ON FOLLOWER DEVELOPMENT AND PERFORMANCE: A FIELD EXPERIMENT
}

\author{
TALY DVIR \\ DOV EDEN \\ Tel Aviv University \\ BRUCE J. AVOLIO \\ University of Nebraska \\ BOAS SHAMIR \\ Hebrew University
}

\begin{abstract}
In a longitudinal, randomized field experiment, we tested the impact of transformational leadership, enhanced by training, on follower development and performance. Experimental group leaders received transformational leadership training, and control group leaders, eclectic leadership training. The sample included 54 military leaders, their 90 direct followers, and 724 indirect followers. Results indicated the leaders in the experimental group had a more positive impact on direct followers' development and on indirect followers' performance than did the leaders in the control group.
\end{abstract}

Transformational leadership theory is a prominent representative of the new theories that have occupied center stage in leadership research in the last two decades. Follower development and follower performance are the targeted outcomes of such leadership (Bass \& Avolio, 1990). However, there has been no conceptual framework, or systematic research, for examining the impact of transformational leadership on follower development (House \& Aditya, 1997). Transformational leadership has been shown to have a positive relationship with performance (Lowe, Kroeck, \& Sivasubramaniam, 1996). Yet a causal relationship between transformational leadership and follower performance has only rarely been demonstrated, because most prior studies have had static, correlational, or nonexperimental designs (Kirkpatrick \& Locke, 1996). The present experiment focused on explor-

The authors thank the Israel Defence Forces (IDF) School for Leadership Development and its consultants, and especially Yitzhak Gonen, Miki Rosenstein, Eliav Zakai, and Sigal Shavit-Traub, for their collaboration in conducting this experiment. Taly Dvir acknowledges the financial support of the Maya Fisher-David Fund, the Josef Buchmann Fund, the Israel Foundation Trustees, and the Faculty of Management at Tel Aviv University. The Lilly and Alejandro Saltiel Chair in Corporate Leadership and Social Responsibility supported Dov Eden's work on this experiment. ing the impact of transformational leadership on follower development and on examining its lasting causal impact on followers' performance.

\section{THEORY AND HYPOTHESES}

\section{Transformational Leadership and Follower Development}

The past two decades have heralded some convergence among organizational behavior scholars concerning a new genre of leadership theories, alternatively referred to as "transformational," "charismatic," and "visionary" leadership. Despite different emphases in each theory, House and Shamir asserted that "it can be safely concluded that there is a strong convergence of the findings from studies with charismatic leadership and those concerned with transformational and visionary leadership" (1993: 84).

The full-range leadership model (Bass \& Avolio, 1990) differentiates between transactional and transformational leaders. Transactional leaders exert influence by setting goals, clarifying desired outcomes, providing feedback, and exchanging rewards for accomplishments. Transformational leaders exert additional influence by broadening and elevating followers' goals and providing them with confidence to perform beyond the expectations specified in the implicit or explicit exchange agreement. Transformational leaders exhibit char- 
ismatic behaviors, arouse inspirational motivation, provide intellectual stimulation, and treat followers with individualized consideration. These behaviors transform their followers helping them to reach their full potential and generate the highest levels of performance.

A principal aspect of transformational leadership is its emphasis on follower development (Avolio \& Gibbons, 1988). Transformational leaders evaluate the potential of all followers in terms of their ability to fulfill current commitments, while also envisioning expansion of their future responsibilities. In contrast, transactional leaders expect followers to achieve agreed-upon objectives but do not encourage them to assume greater responsibility for developing and leading themselves and others (Bass, 1985; Burns, 1978). Although transformational leaders' developing followers to what Bass and Avolio (1990) called their full potential is central to the theory, very little is known about how such leaders so develop followers. This lack of knowledge led House and Aditya to conclude, "There is little evidence that charismatic, transformational, or visionary leadership does indeed transform individuals, groups, large divisions of organizations, or total organizations, despite claims that they do so.... There is no evidence demonstrating stable and long-term effects of leaders on follower self-esteem, motives, desires, preferences, or values" (1997: 443). In the absence of a theory outlining the developmental aspects of transformational leadership, we have integrated different sources to begin building a conceptual framework encompassing three main domains of follower development: motivation, morality, and empowerment.

Motivation. Burns (1978), the originator of transformational leadership theory, referred to two developmental continua. The first concerns follower motivation. Burns proposed that transformational, as compared to transactional, leaders motivate followers in such a way that their primary motive is to satisfy self-actualization needs rather than the lower needs in Maslow's (1954) need hierarchy. Drawing on Burns, Bass $(1985,1998)$ suggested that transformational leaders expand their followers' "need portfolios" by raising them or Maslow's hierarchy. Unlike transactional leaders, who concentrate on fulfilling current follower needs, transformational leaders arouse dormant needs. Bass (1985) also posited that followers' extra effort shows how much a leader motivates them to perform beyond contractual expectations. Thus, emphasis on satisfying self-actualization needs reflects the type of need underlying followers' motivation, and extra effort results from generating higher levels of motivation.
Hypothesis 1a. Transformational leadership has a positive impact on the development of followers' motivation in terms of their selfactualization needs and extra effort.

Morality. Burns's (1978) second developmental continuum, follower moral development, is based on Kohlberg's (1973) theory. Bass (1998) agreed with Burns that to be transformational, a leader must be "morally uplifting." One of the difficulties in investigating moral development is that, according to Kohlberg, moving from one moral stage to the next may take years, a time span rarely encompassed in leadership studies. Shamir, House, and Arthur (1993) provided an alternative for examining moral development, specifying that the creation of value congruence between the leader/organization and followers is one of the processes undertaken by charismatic/transformational leaders. We therefore studied follower internalization of their organization's moral values as a manifestation of moral development. Drawing on Kohlberg, Bass (1985) emphasized the collectivistic aspect of moral development and suggested that transformational leaders get their followers to transcend their self-interest for the sake of the team or organization. This concept is similar to Wagner's (1995) definition of collectivistic orientation. Shamir (1991) also suggested that follower collectivistic orientation is a transformational effect of charismatic leaders.

Hypothesis 1b. Transformational leadership has a positive impact on the development of followers' morality in terms of their internalization of their organization's moral values and a collectivistic orientation.

Empowerment. Transformational leadership theory, in contrast to early charismatic theories, has consistently emphasized followers' development toward autonomy and empowerment over automatic followership (Graham, 1988). Still, research has not clarified whether or not charismatic or transformational leaders are powerful because their followers are weak (Klein \& House, 1995). Scholars consider a critical-independent approach to be an essential empowerment-related process among followers of transformational leaders. For example, Bass and Avolio (1990) stated that transformational leaders enhance followers' capacity to think on their own, develop new ideas, and question outmoded operating rules. Avolio and Gibbons (1988) posited that a major goal of transformational leaders is to develop follower self-management and self-development. Shamir (1991) similarly stressed the transformational effects of charismatic leaders on follower independence. The view that a critical- 
independent approach is an outcome of transformational leadership is also consistent with Kelley's (1992) conceptualization of styles of followership. Kelley's respondents described the best followers as those who "think for themselves," "give constructive criticism," "are their own person," and "are innovative and creative." Kelley's (1992) review of the best, worst, and typical follower characteristics revealed a second dimension, namely, active engagement in the task. The best followers "take initiative," "participate actively," are "selfstarters," and "go above and beyond the job." We therefore define active engagement as the energy invested in the follower role as expressed by high levels of activity, initiative, and responsibility. According to Conger and Kanungo (1988), charismatic leadership is tied to empowerment also through self-efficacy. Shamir et al. (1993) and Avolio and Gibbons (1988) specified increased follower selfefficacy as a developmental effect of transformational leadership. We posited specific self-efficacy as a malleable developmental outcome (Eden, 1990) enhanced among followers of transformational leaders.

Hypothesis 1c. Transformational leadership has a positive impact on the development of followers' empowerment in terms of their critical-independent approach, active engagement in the task, and specific self-efficacy.

\section{Transformational Leadership and Follower Performance}

Three types of studies have examined the relationships between transformational and transactional leadership and performance. Many have used ratings of leadership and outcomes collected from a single source, leaving their results open to common-sourced-common-method bias (e.g., Bycio, Hackett, \& Allen, 1995). Fewer studies have relied on survey data on both leadership and outcomes collected from multiple sources (e.g., Keller, 1992). The smallest number of studies have used multiple sources and multiple methods. These have typically involved questionnaire ratings of leadership and objective performance measures (e.g., Avolio, Waldman, \& Einstein, 1988), or manipulating leadership and measuring outcomes (e.g., Barling, Weber, \& Kelloway, 1996). Overall, there is evidence showing positive relationships between transformational leadership and performance; these relationships are stronger than the relationships between transactional leadership and performance (Lowe et al., 1996). Yet there remains a need for more rigorous field tests of the impact of transformational leadership on objective performance to establish causality (Kirkpatrick \& Locke, 1996).

Hypothesis 2. Transformational leadership has
a positive impact on followers' performance.

\section{Direct and Indirect Leadership}

Direct leadership, or the relationships between focal leaders and their immediate followers, has been studied extensively. In contrast, knowledge of indirect leadership, or the influence of focal leaders on individuals not reporting directly to them, is much more limited. The few attempts to understand indirect leadership have been limited to world-class leaders or highly visible CEOs (Waldman \& Yammarino, 1999). It is assumed that transformational leadership at any level can impact both direct and indirect followers (Yammarino, 1994). There are, however, likely to be differences between the processes that influence close and distant followers (Shamir, 1995). The present experiment included direct and indirect followers. Given the dearth of theory and research, we formulated no hypothesis but took advantage of the opportunity to reveal whatever differences there may be between direct and indirect leadership.

\section{METHODS}

\section{Design and Sample}

This was a field experiment with random assignment of squads of leaders to conditions. The experimental leaders received transformational leadership training, and the control leaders went through routine eclectic leadership training. We predicted that leaders assigned to the experimental training would "enact" significantly more transformational leadership than the control group leaders and then corroborated this difference using a manipulation check. Having generated a higher level of transformational leadership in the experimental condition in phase 1, we then examined its causal impact on follower development and performance in phase 2 .

Phase 1. In phase 1, in the course of their officer training, infantry cadets in the Israel Defense Forces (IDF) went through experimental and control leadership workshops designed to enhance their leadership before they became platoon leaders. The phase 1 sample included 160 cadets in 12 training squads.

Phase 2. After cadets have taken the officer course, the IDF places the new officers in various roles, mostly involving noncomparable perfor- 
mance contexts. On the basis of prior practice, we expected 30 percent of the phase 1 cadets to be assigned as platoon leaders in basic training, where all followers are evaluated using the same measures. To have comparable performance measures for all participating leaders, we tracked this group in phase 2. Of the 160 phase 1 cadets, $54(34 \%)$ were assigned to lead basic training platoons. Phase 2 was conducted during a four-month infantry basic training course, which began a month after the officer course had ended and two months after the leadership workshops. The posttest measurement occurred six months after the leadership workshops. We assessed the impact of the platoon leaders' leadership, previously enhanced by the phase 1 workshops, on their direct followers' (noncommissioned officers', or NCOs') development and their indirect followers' (recruits') development and performance in phase 2 . We collected leadership ratings and developmental data from NCOs and recruits at the beginning and at the end of basic training. In the remainder of this report, these data collections are designated "occasion 1 " and "occasion 2," respectively. Performance grades were rendered at the end of basic training. The phase 2 sample included 54 platoon leaders ( 32 who had gone through the experimental workshops and 22 who had been in the control workshops), 90 NCOs, and 724 recruits. All were men aged 18-22.

\section{Measures}

We pretested measures in a pilot sample of $\mathbf{3 2 0}$ infantry commanders and followers and deleted and revised items on the basis of the pretest. We calculated alpha coefficients for each measure at the group level in line with the unit of randomization, treatment, and analysis.

Manipulation checks. Cadets' initial reactions to the workshop were assessed by 14 items $(\alpha=.95)$ developed for this study. ${ }^{1}$ Cadet knowledge acquisition regarding transformational leadership was evaluated by 11 items developed for this study. Transformational leadership was measured with the 20 transformational leadership items in the short version of Bass and Avolio's Multifactor Leadership Questionnaire 5X (see Avolio, Bass, and Jung [1999] for a discussion of this revised survey). We compared the experimental and control leaders on a global transformational factor, the mean of all transformational items, because our

\footnotetext{
${ }^{1}$ All measures are available from the first author, except the MLQ, which can be obtained from its publisher.
}

goal was to create a higher level of overall transformational leadership among the participants in the experimental condition. The alphas for the global transformational scale ranged between .87 and .92 over two occasions and subsamples.

Development. Except where noted, these measures were the same for recruits and NCOs. Selfactualization needs were evaluated by 10 items based mainly on Hackman and Oldham's (1980) growth needs index. Bass's (1985) three self-report items gauged followers' extra effort. Internalization of organizational moral values was assessed using 17 items completed by the NCOs, with 3 items added for recruits. We based this measure on the 11 values included in the "IDF Code of Ethical Conduct" and on in-depth interviews with IDF personnel regarding incidents that reflect moral dilemmas. The 11 values include perseverance, comradeship, discipline, sanctity of human life, loyalty, personal example, professionalism, purity of arms (which concerns ethical behavior during combat), representation, responsibility, and trustworthiness. Collectivistic orientation was measured using a 7-item scale based on Wagner's (1995) individualism/collectivism questionnaire. Criticalindependent approach was gauged with 16 items developed for this study on the basis of Kelley's (1992) concept of critical-independent thinking. Followers were asked about their thinking and actions regarding themselves, their peers, their leader, and the organization. Active engagement was measured with 12 items developed for this study on the basis of Kelley's (1992) construct. To evaluate self-efficacy, we asked the NCOs to assess their ability to instruct recruits on each of the five subjects taught in basic training, and the recruits estimated their own ability to master each subject. The measure was developed for this experiment on the basis of Dvir, Eden, and Banjo's (1995) index. All but two of the developmental coefficient alphas were above .70 , and most exceeded .80. Alphas were .60 and .69 for self-efficacy and collectivistic orientation, respectively, on one occasion in one subsample. However, because the other three coefficients for each of these measures were above .70, we viewed them as reliable.

Performance. Recruits' performance was assessed by five routine IDF objective tests: light weapons (written test), light weapons (practical test), physical fitness, obstacle course, and marksmanship. Leadership in this setting extends beyond conveying technical or physical skills; it also involves developing the recruits' understanding of the meaning of these tasks for overall unit performance. 


\section{Procedures}

Twelve trainers at the IDF School for Leadership Development participated. All were experienced in delivering the eclectic leadership workshop. Seven trainers were randomly assigned to a five-day preliminary workshop to train them in delivering the new transformational leadership model to the experimental cadets in phase 1 . The five control trainers received no preliminary workshop. To preclude compensatory rivalry, we promised the control trainers that they would receive the new training after the experiment.

We assigned squads of cadets, rather than individuals, to conditions because most training activities in officer courses are done in squads. We randomly assigned seven squads to the transformational leadership condition and five to the control condition. Three-day leadership workshops were given to the cadets in both conditions. The experimental workshop ${ }^{2}$ embodied the major propositions of transformational leadership theory. It was built around four core themes that were conveyed to the cadets in every workshop activity: (1) Transformational and transactional leadership are different lenses through which a leader can view relationships with followers. (2) Transformational leadership is enacted through a set of behaviors. (3) Transformational leadership can create higher levels of development and performance among followers than can transactional leadership. (4) Followers of transformational leaders should be continuously developed to higher levels of motivation, morality, and empowerment. The eclectic leadership workshop delivered to control leaders was based on discussing "here and now" individual and group processes with a psychodynamic focus. The trainer related processes that occurred in the workshop to various concepts, such as goal setting, self-fulfilling prophecy, crisis intervention, contingency theory, trust building, personal example, and group cohesion. Both the experimental and the control workshops employed role playing, group discussions, simulations, presentations and examples, video cases, and peer and trainer feedback. A month and a half after the workshops, before the leaders began their first leadership role, the trainers worked with the experimental leaders for three hours to reinforce the treatment. Because of budgetary constraints, we could not conduct booster sessions with the control leaders.

After the experiment, when it could no longer

${ }^{2}$ A full description of the experimental and control workshops is available upon request from the first author. affect the results, we conducted a five-day workshop for the control trainers. The purpose was to enrich them with the knowledge and skills provided earlier to the experimental trainers and satisfy the need for equitable treatment.

\section{Analysis}

Multivariate analyses of variance (MANOVA) and covariance (MANCOVA) were used to test whether the treatment affected development and performance. To estimate the differential effects on each developmental and performance variable, we used one-way analysis of variance (ANOVA) for variables measured once after the treatment and repeated-measures ANOVA for variables measured twice. We computed correlations to estimate effect sizes and used the binomial effect size display (BESD) to express the practical impact of the treatment (Rosenthal \& Rubin, 1982). When the treatment-by-occasion interaction was significant, we conducted simple-effects tests of the changes over time in each condition. To reduce the likelihood of type 2 error, we followed Sauley and Bedeian's (1989) recommendation and interpreted results significant beyond the .10 level as trends in the data. In phase 1, squads were assigned to conditions, and thus the analyses were done at the squad level. In phase 2, 54 platoon leaders from the 12 experimental and control squads participated. Therefore, data collected in phase 2 were aggregated to, and analyzed at, the platoon level.

Pretest data are typically collected prior to a treatment. In the present experiment, the first round of phase 2 data collection took place only two weeks into basic training. We could not expect enhanced transformational leadership among experimental leaders to be evident so early into basic training, when followers had so little exposure to their leaders. We expected the experimental leaders to become more transformational as they had more interaction with their followers over time. Therefore, we regarded the first round of phase 2 leadership and development data as a pretest and used the occasion-treatment interactions to test differences between experimental and control conditions in the amount of before/after change for variables measured twice.

\section{RESULTS}

\section{Manipulation Checks}

The first manipulation check examined how the leaders perceived the workshops. We did not expect a difference in how favorably they regarded 
the workshops, nor did we find one $(\bar{x}=5.27$, s.d. $=0.46$, and $\bar{x}=5.39$, s.d. $=0.42$ for the experimental and control conditions, respectively; $F_{1,11}=0.22$, n.s.). Thus, participants in both conditions got equally positively regarded leadership training. The second manipulation check revealed that the experimental leaders acquired more knowledge of transformational leadership theory than the control leaders $(\bar{x}=79.0$, s.d. $=7.0$, and $\bar{x}$ $=56.0$, s.d. $=3.0$, respectively; $F_{1,11}=43.49, p<$ .001 ). The third manipulation check tested whether the training produced more transformational leadership behavior among the experimental leaders. The interaction of treatment and occasion was significant for NCO ratings of the platoon leaders' transformational leadership $\left(F_{1,43}=4.43, p<.05\right)$. This interaction was not significant among the recruits $\left(F_{1,52}=0.07\right.$, n.s. $)$.

\section{Direct and Indirect Followers' Development}

MANCOVA revealed a significant treatment effect $\left(F_{7,30}=2.44, p<.05\right)$ for the combination of the seven developmental variables among NCOs after adjustment for pretest differences. Table 1 presents the means and the summary of the ANOVA of each developmental variable among the NCOs. The treatment-occasion interaction was significant for self-efficacy, critical-independent approach, and extra effort, and nearly significant $(p=.06)$ for collectivistic orientation.
The self-efficacy means showed the interaction stemmed from an increase in ratings in the experimental group and a decrease in the control group. Simple-effects tests showed the experimental increase approached significance $\left(F_{1,43}=3.42, p<\right.$ .10), whereas the decline in the control condition was not significant. The BESD equivalent of the interaction effect size $(r=.31)$ is a success rate of 65 percent for the experimental platoons versus 35 percent for the control platoons. Mean critical-independent approach declined in the control group $\left(F_{1,43}=11.12, p<.01\right)$ and remained unchanged in the experimental group. The BESD equivalent of the interaction effect size $(r=.38)$ is a success rate of 69 percent versus 31 percent. Mean extra effort decreased sharply over time in the control condition $\left(F_{1,43}=7.49, p<.05\right)$, whereas the change in the experimental group was not significant. The BESD equivalent of the interaction effect size $(r=$ .30) is a success rate of 65 versus 35 percent. Mean collectivistic orientation increased in the experimental condition and decreased in the control condition. Simple-effects tests revealed that neither change was significant. The BESD equivalent of the interaction effect size $(r=.28, p=.06)$ is a success rate of 64 versus 36 percent. Because there were so few degrees of freedom in these group-level analyses, we interpreted a significance level of .06 as preliminary confirmation of the positive impact of transformational leadership on direct followers' collectivistic orientation. Table 1 shows no signif-

TABLE 1

Means, Standard Deviations, and Summary of Repeated-Measures Analyses of Variance of Development among Direct Followers ${ }^{a}$

\begin{tabular}{|c|c|c|c|c|c|c|}
\hline \multirow[b]{2}{*}{ Variable } & \multirow[b]{2}{*}{ Occasion } & \multicolumn{2}{|c|}{ Experimental } & \multicolumn{2}{|c|}{ Control } & \multirow{2}{*}{$\begin{array}{c}F \text { for the } \\
\text { Treatment-by- } \\
\text { Occasion } \\
\text { Interaction }\end{array}$} \\
\hline & & Mean & s.d. & Mean & s.d. & \\
\hline \multirow[t]{2}{*}{ Self-efficacy } & 1 & 4.54 & 0.32 & 4.64 & 0.31 & \\
\hline & 2 & 4.70 & 0.26 & 4.51 & 0.57 & $4.55^{\star}$ \\
\hline \multirow[t]{2}{*}{ Collectivistic orientation } & 1 & 6.01 & 0.60 & 5.82 & 0.68 & \\
\hline & 2 & 6.17 & 0.50 & 5.52 & 1.03 & $3.59^{b}$ \\
\hline \multirow[t]{2}{*}{ Critical-independent approach } & 1 & 3.96 & 0.31 & 4.02 & 0.34 & \\
\hline & 2 & 3.96 & 0.40 & 3.77 & 0.47 & $7.07 \star \star$ \\
\hline \multirow[t]{2}{*}{ Extra effort } & 1 & 3.74 & 0.56 & 3.73 & 0.49 & \\
\hline & 2 & 3.71 & 0.75 & 3.25 & 0.91 & $4.11 *$ \\
\hline \multirow[t]{2}{*}{ Active engagement } & 1 & 4.10 & 0.34 & 4.02 & 0.39 & \\
\hline & 2 & 3.92 & 0.39 & 3.67 & 0.75 & 1.46 \\
\hline \multirow[t]{2}{*}{ Internalization of moral values } & 1 & 3.97 & 0.35 & 3.97 & 0.46 & \\
\hline & 2 & 3.90 & 0.40 & 3.74 & 0.51 & 1.94 \\
\hline \multirow[t]{2}{*}{ Self-actualization needs } & 1 & 4.44 & 0.45 & 4.51 & 0.32 & \\
\hline & 2 & 4.36 & 0.41 & 4.26 & 0.74 & 0.81 \\
\hline
\end{tabular}

\footnotetext{
a $n=27$ experimental platoons and 18 control platoons.

${ }^{\mathrm{b}} p=.06$.

${ }^{*} p<.05$

$\star * p<.01$
} 
icant treatment-by-occasion effects for the NCOs' active engagement, internalization of moral values, and self-actualization needs; nevertheless, the means changed in the hypothesized direction. For these variables, the BESD equivalent of the mean interaction effect size $(r=.17)$ is a success rate of 59 percent for the experimental platoons versus 41 percent for the control platoons.

The MANCOVA of the developmental variables among the recruits showed no significant treatment effect, and repeated-measures ANOVA showed no significant treatment-by-occasion interactions.

Indirect followers' performance. MANOVA detected a significant treatment effect $\left(F_{5,26}=3.45\right.$, $p<.02$ ) for the combination of the five performance measures. The means in Table 2 show that the experimental platoons outperformed the control platoons in every performance area. One-way ANOVA detected significant treatment effects on the written light weapons test and on the obstacle course. The treatment effect approached significance $(p<.08)$ for the practical light weapons test even though the degrees of freedom in this analysis were reduced from 41 to 32 owing to incomplete data for nine platoons. The BESD equivalent of the effect size $(r=.32)$ for written light weapons is a success rate of 66 percent for the experimental platoons versus 34 percent for the control platoons; for practical light weapons $(r=.31), 65$ versus 35 percent; and for the obstacle course $(r=.52), 76$ versus 24 percent. The treatment effects for physical fitness and marksmanship were not significant.

Post hoc correlational analyses. We computed correlations between the developmental variables and performance at the platoon level. Very few significant relationships were found between the recruits' or the NCOs' developmental variables and the recruits' performance grades in both conditions. However, most of the correlations between the NCO developmental variables and recruit developmental variables were higher for the participants who were in the experimental condition than for those who were in the control condition. In 36 of 49 pairs of correlations, the experimental correlation was higher than the control correlation. Fisher's $r$-to- $Z$ transformation revealed that the difference was marginally significant $(p<.10)$ for 11 pairs of correlations. For 9 pairs, the correlation in the experimental platoons was significantly higher than the correlation in the control platoons.

\section{DISCUSSION}

\section{Theoretical and Practical Implications}

The more positive impact of the transformational leaders on direct follower development and on indirect follower performance confirms core causal propositions of transformational leadership theory. Moreover, the positive impact of the transformational leaders on their indirect followers' performance experimentally strengthens conclusions drawn from previous studies, mostly conducted with causally ambiguous designs.

The newly proposed conceptual framework for developmental aspects of transformational leadership theory was partially confirmed. Transformational leadership enhanced at least one measure each of motivation, morality, and empowerment among the direct followers. However, the impact of transformational leadership was not confirmed for direct followers' active engagement, internalization

TABLE 2

Means, Standard Deviations, and Summary of Analyses of Variance of Performance among Indirect Followers ${ }^{\mathrm{a}}$

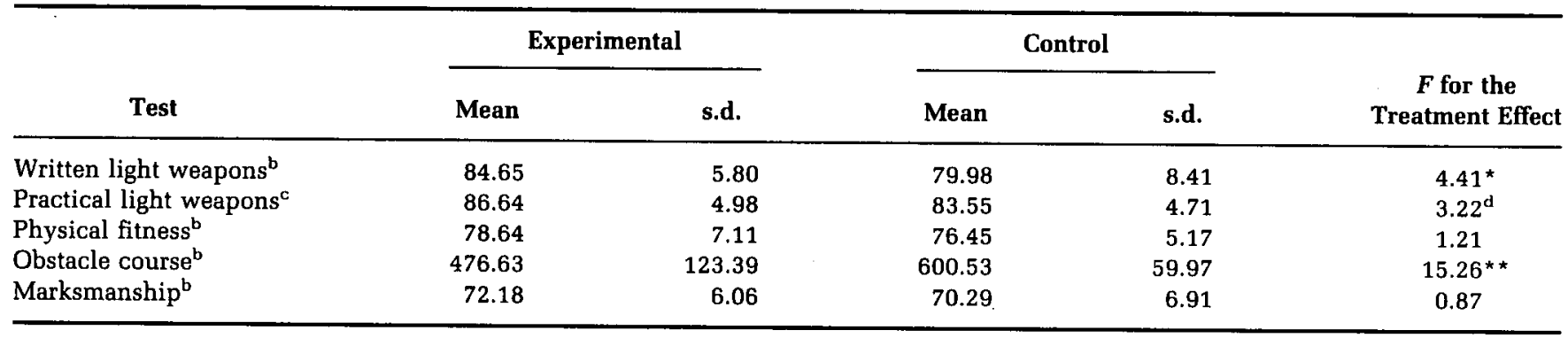

\footnotetext{
a The grades for all tests, except for the obstacle course, ranged from 0 to 100 . Obstacle course results are presented in seconds in such a way that a lower score represents better performance.

${ }^{b} n=23$ experimental platoons and 18 control platoons.

${ }^{c} n=17$ experimental platoons and 15 control platoons.

${ }^{\mathrm{d}} p<.08$.

${ }^{\star} p<.05$

${ }^{\star \star} p<.01$
} 
of moral values, and self-actualization needs. Because the means of all of these variables were in the hypothesized direction, we conclude that more testing is needed before revising the proposed developmental framework. Transformational and charismatic leadership theories are still at early stages of specifying the developmental mediating processes between leader behavior and performance (Shamir, 1991). The first step toward confirming the hypothesis that follower development can mediate effects on performance is to show that transformational leadership affects development as well as performance. The present results support these links among direct followers. The next step is to develop specific hypotheses linking specific leadership styles, developmental variables, and performance measures in a broader range of contexts.

The more positive impact of the experimental leaders on their direct followers' development appeared to prevent decline in some developmental variables. In the arduous and stressful context of this experiment, the positive impact of a leader on follower development may be evidenced by averting demoralization or regression in feelings about oneself. Given the dynamic nature of personnel assignments and work flow, organizational restructuring, downsizing, and takeovers and mergers, a positive transformational leadership effect may be evidenced by halting motivational, moral, or empowerment decline among followers. We suggest that theoretical formulations should incorporate the prevention of developmental regression as a positive outcome of transformational leadership.

Our experimental leaders affected their indirect followers' performance without seemingly affecting their self-perceived development. The present findings suggest that complex dynamics among the direct and indirect followers may in turn affect performance. The stronger relationships between the direct and indirect followers' ratings on the measures of developmental variables in the experimental group may indicate that transformational leaders create a stronger social bond among their direct and indirect followers, thus improving the indirect followers' performance. Other explanations are also possible. First, transformational leadership theory explains the effects of leadership on both immediate and long-term processes and outcomes. Effects on indirect follower development may take longer (Avolio \& Bass, 1988). Perhaps the present experimental leaders planted developmental seeds among their indirect followers, and more time was needed for these seeds to germinate. This idea is especially relevant in the present context, because recruits (as opposed to NCOs) are typically more performance- than development-oriented.
Perhaps the stressful context suppressed the predicted developmental effects among the recruits, who bore the brunt of this stress. Second, platoon leaders spend much less time with their indirect followers than with their direct followers, thereby restricting the leaders' impact on the former's development. Perhaps a critical level of interaction with a transformational leader is indispensable for the impact on follower development to emerge; the direct followers' interaction may have been above this threshold level, and the indirect followers', below it. Finally, it is possible that other, unmeasured, variables played a crucial role in enhancing the indirect followers' performance. For example, group developmental processes (for instance, platoon cohesiveness, potency, or culture) may have mediated the impact of leadership on recruit performance.

\section{Limitations and Future Research}

Examining the effects of global transformational leadership renders it impossible to pinpoint the specific components of transformational leadership that contributed to the effects produced. Future research should add treatment conditions and focus on specific aspects of transformational leadership, as Kirkpatrick and Locke (1996) did in their laboratory experiment on visionary leadership.

The fact that a booster session was offered only to the experimental group raises the possibility of a Hawthorne effect (whereby the attention given to participants in an experiment may improve their attitudes and performance). We could not obtain permission for a control booster. Faced with either foregoing the booster altogether and risking failure at enhancing transformational leadership, or compromising internal validity by giving the booster only to the experimental leaders, we chose the latter. However, in a military context, where personnel are accustomed to participating in various curricula, going through different programs did not appear to be an issue for participants. We are unable to rule out the possibility that the booster session given only to the experimental leaders accounted for some of the effects, but we believe that this threat to internal validity in the present experiment was relatively low.

According to Klein and House (1995), in homogeneous charismatic relationships the leader shares charismatic relationships with all followers or with none. In nonhomogeneous cases, the leader shares charismatic relationships with a select few followers. Thus, the theory allows for either homogeneous or variable charismatic effects on followers. 
Our analyses used the platoon as the unit of analysis in line with the treatment level. We do not claim that the platoon means in the present experiment represent homogeneous group effects, and aggregating to the platoon level may have masked some of the variance within platoons. However, we could not address this issue better because the number of NCOs in each platoon was both small and variable.

Finally, the idiosyncrasy of a military organization limits the external validity of our experiment. Replication in civilian organizations with mixedgender and older participants is needed. Yet many organizational features in our sample are not unique to the military. Adherence to hierarchy and professionalism, a salient organizational mission that depends on strong individual commitment, demanding and stressful jobs in which leaders and followers spend most of their time, and the need to work with direct and indirect followers characterize many organizations. Indeed, the positive effects of transformational leadership have been confirmed in civilian as well as in military samples (Bass, 1998). We conclude that transformational leadership, enhanced by training, can augment the development of human resources and their performance in a variety of organizational contexts.

\section{REFERENCES}

Avolio, B. J., \& Bass, B. M. 1988. Transformational leadership, charisma and beyond. In J. G. Hunt, H. R. Baliga, H. P. Dachler, \& C. A. Schriesheim (Eds.), Emerging leadership vistas: 29-49. Lexington, MA: Heath.

Avolio, B. J., Bass, B. M., \& Jung, D. I. 1999. Reexamining the components of transformational and transactional leadership using the Multifactor Leadership Questionnaire. Journal of Occupational and Organizational Psychology, 72: 441-462.

Avolio, B. J., \& Gibbons, T. C. 1988. Developing transformational leaders: A life span approach. In J. A. Conger \& R. N. Kanungo (Eds.), Charismatic leadership: The elusive factor in organizational effectiveness: 276-308. San Francisco: Jossey-Bass.

Avolio, B. J., Waldman, D. A., \& Einstein, W. O. 1988. Transformational leadership in a management simulation: Impacting the bottom line. Group and Organization Studies, 13: 59-80.

Barling, J., Weber, T., \& Kelloway, K. E. 1996. Effects of transformational leadership training on attitudinal and financial outcomes: A field experiment. Journal of Applied Psychology, 81: 827-832.

Bass, B. M. 1985. Leadership and performance beyond expectations. New York: Free Press.

Bass, B. M. 1998. Transformational leadership: Indus- try, military, and educational impact. Mahwah, NJ: Erlbaum.

Bass, B. M., \& Avolio, B. J. 1990. The implications of transactional and transformational leadership for individual, team, and organizational development. In R. W. Woodman \& W. A. Pasmore (Eds.), Research in organizational change and development, vol. 4: 231-272. Greenwich, CT: JAI Press.

Burns, J. M. 1978. Leadership. New York: Harper \& Row.

Bycio, P., Hackett, R. D., \& Allen, J. S. 1995. Further assessments of Bass's (1985) conceptualization of transactional and transformational leadership. Journal of Applied Psychology, 80: 468-478.

Conger, J. A., \& Kanungo, R. N. 1988. Behavioral dimensions of charismatic leadership. In J. A. Conger \& R. N. Kanungo (Eds.), Charismatic leadership: The elusive factor in organizational effectiveness: 7897. San Francisco: Jossey-Bass.

Dvir, T., Eden, D., \& Banjo, M. L. 1995. Self-fulfilling prophecy and gender: Can women be Pygmalion and Galatea? Journal of Applied Psychology, 80: 253270.

Eden, D. 1990. Pygmalion in management: Productivity as a self-fulfilling prophecy. Lexington, MA: Lexington Books.

Graham, J. W. 1988. Transformational leadership: Fostering follower autonomy, not automatic leadership. In J. G. Hunt, R. B. Baliga, P. H. Dachler, \& C. A. Schriesheim (Eds.), Emerging leadership vistas: 73-79. Lexington, MA: Lexington Books.

Hackman, J. R., \& Oldham, G. R. 1980. Work redesign. Reading, MA: Addison-Wesley.

House, R. J., \& Aditya, R. M. 1997. The social scientific study of leadership: Quo vadis? Journal of Management, 23: 409-473.

House, R. J., \& Shamir, B. 1993. Toward the integration of transformational, charismatic, and visionary theories. In M. M. Chemers \& R. Ayman (Eds.), Leadership theory and research: Perspectives and directions: 81-107. San Diego: Academic Press.

Kelley, R. E. 1992. The power of followership. New York: Currency and Doubleday.

Keller, R. T. 1992. Transformational leadership and the performance of research and development project groups. Journal of Management, 18: 489-501.

Kirkpatrick, S. A., \& Locke, E. A. 1996. Direct and indirect effects of three core charismatic leadership components on performance and attitudes. Journal of Applied Psychology, 81: 36-51.

Klein, K. J., \& House, R. J. 1995. On fire: Charismatic leaders and levels of analysis. Leadership Quarterly, 6: 183-198.

Kohlberg, L. 1973. Stages and aging in moral development: Some speculations. Gerontologist, 13: 497502. 
Lowe, K. B., Kroeck, K. G., Sivasubramaniam, N. 1996. Effectiveness correlates of transformational and transactional leadership: A meta-analytic review of the MLQ literature. Leadership Quarterly, 7: 385425.

Maslow, A. H. 1954. Motivation and personality. New York: Harper.

Rosenthal, R., \& Rubin, D. B. 1982. A simple general purpose display of magnitude of experimental effects. Journal of Educational Psychology, 74: 166169.

Sauley, K. S., \& Bedeian, A. G. 1989. .05: A case of the tail wagging the distribution. Journal of Management, 15: 335-344.

Shamir, B. 1991. The charismatic relationship: Alternative explanations and predictions. Leadership Quarterly, 2: 81-104.

Shamir, B. 1995. Social distance and charisma: Theoretical notes and exploratory study. Leadership Quarterly, 6: 19-47.

Shamir, B., House, R. J., \& Arthur, M. B. 1993. The motivational effects of charismatic leadership: A selfconcept based theory. Organization Science, 4(2): 1-17.

Wagner, J. A. 1995. Studies of individualism-collectivism: Effects on cooperation in groups. Academy of Management Journal, 38: 152-172.

Waldman, D. E., \& Yammarino, F. J. 1999. CEO charismatic leadership: Levels-of-management and levelsof-analysis effects. Academy of Management Review, 24: $266-285$.

Yammarino, F. J. 1994. Indirect leadership: Transformational leadership at a distance. In B. M. Bass \& B. J. Avolio (Eds.), Improving organizational effectiveness through transformational leadership: 26-47. Thousand Oaks, CA: Sage.

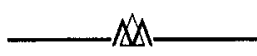

Taly Dvir (talyd@post.tau.ac.il) is a lecturer in management and organizational behavior at the Faculty of Management, Tel Aviv University. She earned her Ph.D. in management from Tel Aviv University. Her current research interests include transformational and charismatic leadership, followership, leadership and emotions, and leadership differences in high- and low-tech firms.

Dov Eden is the Lilly and Alejandro Saltiel Professor of Corporate Leadership and Social Responsibility at the Faculty of Management, Tel Aviv University. He earned his Ph.D. in organizational psychology at the University of Michigan. His current research interests include leadership, motivation, self-fulfilling prophecy at work, practical application of organizational behavior theory through management training, and job stress and vacation relief.

Bruce J. Avolio is the Don and Shirley Clifton Chair in Leadership in the Department of Management and College of Business Administration at the University of $\mathrm{Ne}$ braska. His current research interests include how leadership is affected by the introduction of new information technology in organizations and how e-leadership differs from leadership that is not mediated by technology. He is also examining how information technology can be used to augment and accelerate leadership development over time.

Boas Shamir is a professor in the Department of Sociology and Social Anthropology, Hebrew University of Jerusalem. He holds a Ph.D. in social psychology from the London School of Economics and Political Science. His current research interests include leadership, followership, and trust in organizations.

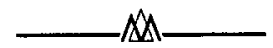

